\title{
Validation of the Brazilian version of the Expanded Prostate Cancer Index Composite (EPIC) for patients submitted to radical prostatectomy
}

\author{
Enaury Alves, Rebecca Medina, Cássio Andreoni \\ Department of Urology, Escola Paulista de Medicina da Universidade Federal de São Paulo, EPM/ \\ UNIFESP - Sao Paulo, SP, Brazil
}

\section{ABSTRACT}

Objectives: Validation of the Expanded Prostate Cancer Index Composite (EPIC) questionnaire translated to Portuguese. This is an evaluation tool of the effects of treatment on quality of life of patients with prostate cancer.

Materials and Methods: In order to translate and validate, several recommended methodological techniques in the literature were included: initial translation, synthesis of translation, board committee review and back translation. Sample included 40 patients with localized prostate cancer submitted to surgical retropubic radical prostatectomy from 2008 to 2010.

Results: The internal consistency analysis of the scales of the questionnaire resulted in alpha Cronbach coefficients "very good" $(>0.9)$ and "good" $(>0.8)$ to 8 of 14 domains. The higher coefficients (0.94) were assigned to sexual score, subscales incontinence and sexual function. Post-operatory follow-up ranged from 3 to 35 months, median 18.7 months. Conclusions: The Brazilian version of EPIC is reliable and valid, and is a useful tool to evaluate the impact of retropubic radical prostatectomy on quality of life of Brazilian patients with localized prostate cancer, in national and internationals studies.

\section{ARTICLE INFO}

Key words:

Prostatic Neoplasms; Validation Studies [Publication Type]; Prostatectomy; Quality of Life; Questionnaires; Translations

Int Braz J Urol. 2013; 39: 344-52

Submitted for publication:

February 02, 2012

Accepted after revision:

May 29, 2013

\section{INTRODUCTION}

Prostate cancer is the sixth most common cancer in the World, representing 10\% of all tumors. In Brazil, it is the second most common cancer among men (behind non-melanoma skin cancer), and it is 52.350 new cases are estimated in 2010, or an estimated risk of 54 new cases per 100.000 men. The rise of incidence is due to the diagnosis of asymptomatic patients, the rise of life expectancy and the improvement of the information systems of the country. The incidence raised mainly in areas of the country whe- re surveillance is common (1). The diagnosis of prostate cancer is made through rectal exam and prostate specific antigen essay (PSA) and confirmation with ultrasound-guided prostate biopsy. According to the recommendations of the Brazilian Society of Urology, the preventive exam must be done after 45 years of age, and for those with family history of prostate cancer after 40 years of age $(2,3)$.

Prostate cancer treatment depends of the staging of the disease, histological grade, patient age and general status of the patient. To localized tumors, surgery is an option (radical pros- 
tatectomy), as well as external radiotherapy or brachytherapy. To localized advanced tumors, it has been used surgery or radiotherapy combined with hormone therapy, and to metastatic disease, the treatment of choice is hormone therapy (4).

However, all therapeutic options have collateral effects (radical prostatectomy, brachytherapy and external radiotherapy), such as urinary incontinence, erectile dysfunction and intestinal alterations. The evaluation of the treatment must address not only the survival but the negative impact on quality of life of patients $(5,6)$.

Quality of life evaluation related to health includes all aspects of patient evaluation and can verify the impact of the disease, health and treatment (7). The used questionnaires to evaluate quality of life are useful to transform subjective measures in objectives evaluations in order to quantify and analyze specific and global aspects $(8,9)$.

World Health Organization (WHO) defines quality of life as the individual perception of his role in life, in relation to his (her) objectives, expectations, patterns and worries, in culture and values contexts. It is a broad and complex concept that encompass physical health, psychological status, independence level, social relations, personal beliefs, and relation to environment $(10,11)$.

\section{MATERIALS AND METHODS}

EPIC questionnaire is a self-administered tool and is intended to evaluate the impact of treatment on quality of life of patients with prostate cancer. It includes 50 questions, of four domains: urinary, intestinal, sexual and hormonal; it evaluates the last four weeks and includes a Likert scale of answers of 5 options. Each domain contains two subscales (function and nuisance). The urinary domain still has two additional subscales: incontinence and irritative/obstructive symptoms (12).

\section{Procedures for translation and validation}

The translation and validation of the questionnaire was performed in four steps: initial translation, translation synthesis, board committee of specialists review and back translation, according to the criteria described by Guillemin et al (13).

\section{Initial translation}

Question translation was performed by two independent translators, fluent in English and aware of the study objectives.

\section{Translation Synthesis}

Production of a synthesis of the two translated versions carried out by the researcher and leader, maintaining the same fundamental characteristics of the original questionnaire.

\section{Review by a Board of Specialists Committee}

A committee of specialists included five urologists fluent in English that evaluated for each question the semantic, idiomatic, cultural and conceptual equivalents between the original and the translated version.

Semantic equivalence refers to the meaning of the words (grammar and vocabulary), while idiomatic equivalence refers to colloquial expressions that are equivalent to the original idiom. Cultural equivalence refers to the lived experiences in the cultural context of society. The conceptual equivalence refers to the words with different cultural meaning (14).

A first final version in Portuguese was proposed during the meeting of the panel of specialists, the leader and the researcher, after joint evaluation of instructions, questions and format.

\section{Back Translation}

During back translation, the questionnaire was translated again, but this time from Portuguese to English, by two native English translators with domain of the Portuguese language, who did not know the objectives of the study or the original questionnaire. Afterwards, they compared the translation with the original and did not find any discrepancy.

\section{Population and Sampling}

The sample included 40 male patients randomly selected in the ambulatory of Urology of Hospital São Paulo, with the following inclusion criteria: a) diagnosis of localized prostate cancer; b) clinical stage T1 or T2; c) did not receive any previous treatment for prostate cancer; d) therapeutic indication of retropubic radical prostatectomy. 


\section{Ethical Aspects}

Initially, an e-mail authorization was referred to the authors of EPIC in order to translate and validate the original to Portuguese. After that authorization, the research was approved by the Ethical Committee of Research of the Federal University of São Paulo. All patients signed an Informed Consent.

\section{Statistical analysis}

In this phase, the same procedure adopted by the original EPIC study was performed, allowing the evaluation of a total sample of heterogeneous patients regarding the impact of treatment on the domains: urinary, intestinal, sexual and hormonal. The tests were performed using the quality of life scores obtained after treatment.

To internal consistency analysis, in order to verify the reliability of the instrument (15), it was used the statistical alpha test of Cronbach (16). This index varies from 0 to 1 . The closest to 1 , the higher the reliability of the instrument. Intern consistency was considered: very good, if superior to 0.9 ; good, between 0.8 and 0.9 ; reasonable, between 0.7 and 0.8 ; weak, between 0.7 and 0.8 ; and poor, between 0.6 and 0.7 ; it was considered inadmissible if inferior to 0.6. It there is no variance between the individual items, the alpha score is 1: all items of the instrument are totally homogeneous, producing exactly the same variance $(17,18)$.

The significance level for the statistical tests was $5 \%$, or $p<0.05$. Data analysis was made using the software SPSS - Statistical Package for Social Science.

\section{RESULTS}

Socio-demographic characteristics of the 40 patients are described in Table-1. Median age was $63.8 \pm 8.6$ years, varying from 46 to 78 years, and $70 \%$ of patients were married or had a fixed partner.

Table-2 depicts the results of intern consistency, median and standard deviation for the 14 domains (4 summaries and 10 subscales) of the Brazilian version of EPIC. The internal consistency analysis of the scales of the questionnaire resulted in Cronbach alpha coefficients "very good" above 0.9 and "good" above 0.8 to 8 of them, and the higher scores were obtained for the sexual score, subscales incontinence and sexual function. When we compared these data with the original version and the Spanish version (Table-3), it is observed that they are similar, without significant differences.

Table- 4 shows the data for patients older than 65 or with less than 65 years and EPIC scores. It is observed that as the age rises, there is a decline of the scores "sexual domain", 'sexual function", "incontinence" and "urinary distress".

Table 1 - Socio-demographic profile.

\begin{tabular}{ll}
\hline Age & \\
\hline Median & $63.8 \%$ \\
Standard Deviation & 8.6 \\
Minimum & 46 \\
Maximum & 78 \\
Colour / Race & \\
White & \\
Black & $42.5 \%$ \\
Brown & $42.5 \%$ \\
Marital Status & $15.0 \%$ \\
Married/fixed partner & \\
Single & $70.0 \%$ \\
Widow & $12.5 \%$ \\
Divorced & $15.0 \%$ \\
Schooling & $2.5 \%$ \\
Illiterate / Incomplete basic school \\
Complete basic school/Incomplete \\
high school \\
Complete high school /Incomplete \\
higher education \\
Complete higher education \\
\hline \\
\hline
\end{tabular}


Table 2 - Descriptive measures of EPIC.

\begin{tabular}{|c|c|c|c|}
\hline HRQOL Domain & Number of itens & Mean Score (sd) & $\begin{array}{l}\text { Internal consistency } \\
\text { reliability }\end{array}$ \\
\hline \multicolumn{4}{|c|}{ HRQOL Domain Summary Scores } \\
\hline Urinary & 12 & $82.2(12.1)$ & 0.87 \\
\hline Bowel & 14 & $96.7(2.1)$ & 0.81 \\
\hline Sexual & 13 & $35.2(16.3)$ & 0.94 \\
\hline Hormonal & 11 & $94.0(9.2)$ & 0.74 \\
\hline \multicolumn{4}{|c|}{ Domain-Specific HRQOL Subscales } \\
\hline \multicolumn{4}{|l|}{ Urinary Subscales } \\
\hline Function & 5 & $82.9(14.9)$ & 0.69 \\
\hline Bother & 7 & $81.7(11.0)$ & 0.84 \\
\hline Incontinence & 4 & $73.0(8.7)$ & 0.94 \\
\hline Irritative/Obstructive & 7 & $89.3(9.5)$ & 0.78 \\
\hline \multicolumn{4}{|l|}{ Bowel Subscales } \\
\hline Function & 7 & $96.2(2.5)$ & 0.53 \\
\hline Bother & 7 & $97.1(1.6)$ & 0.87 \\
\hline \multicolumn{4}{|l|}{ Sexual Subscales } \\
\hline Function & 9 & $29.1(14.0)$ & 0.94 \\
\hline Bother & 4 & $48.9(13.1)$ & 0.93 \\
\hline \multicolumn{4}{|l|}{ Hormonal Subscales } \\
\hline Function & 5 & $89.7(12.8)$ & 0.57 \\
\hline Bother & 6 & $97.6(2.0)$ & 0.66 \\
\hline
\end{tabular}

Post-operatory follow-up varied from 3 to 35 months, median 18.7 months, with minimal significant correlations of the following EPIC scores: "domain and urinary function", "irritative/obstructive", "domain, function and intestinal distress" and "hormonal distress"). It is observed that as the time passes, the scores tend to decrease (Table-5).

\section{DISCUSSION}

The literature highly recommends the adaptation of scales and questionnaires previously validated, due to reduction of costs, a standardization of measure for investigation in different cultures, allowing international studies to compare the same phenomena in several cultures (19). 


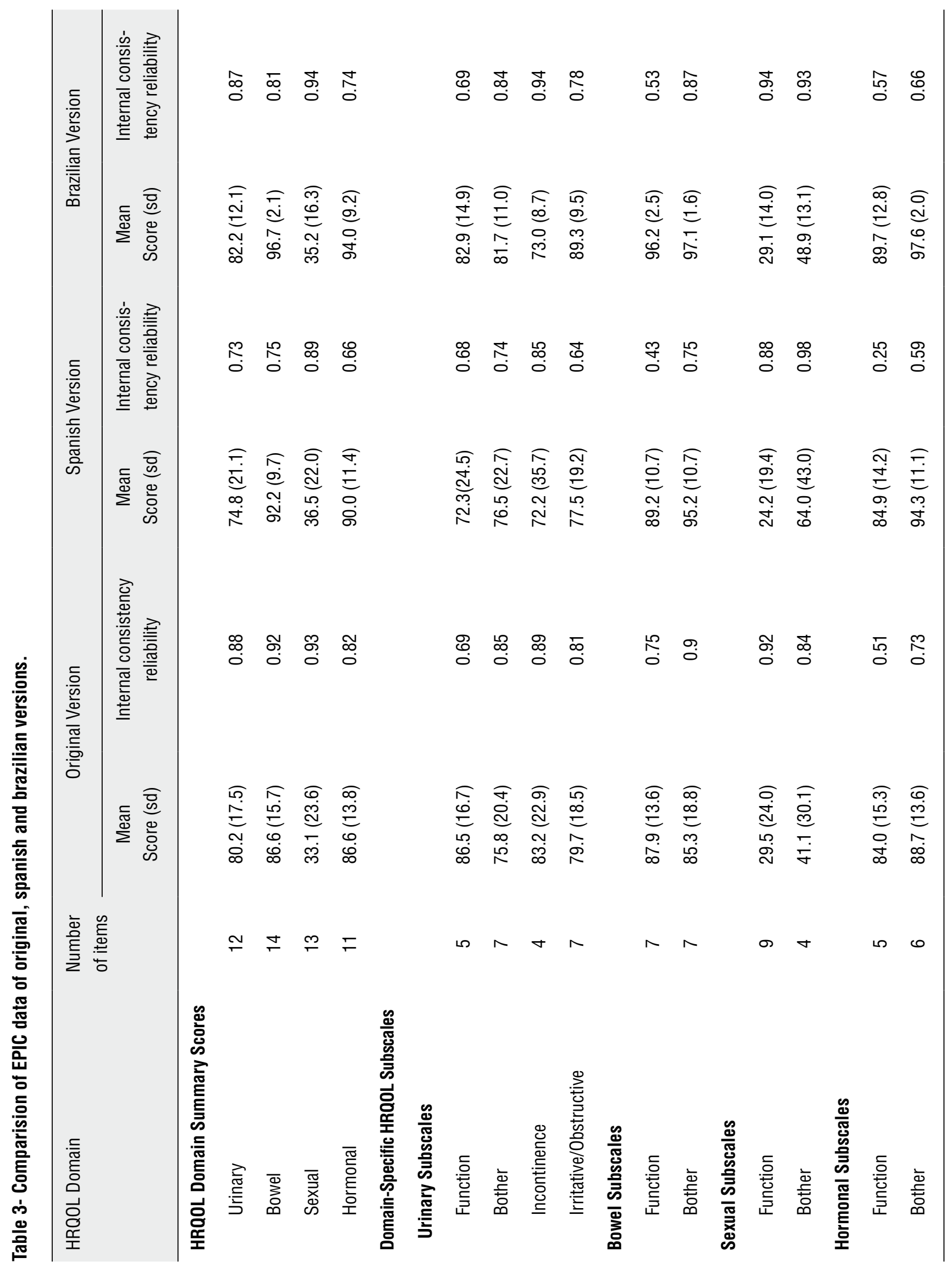


Table 4 - Correlation of EPIC score and age.

\begin{tabular}{|c|c|c|c|c|c|}
\hline \multirow[t]{2}{*}{ HRQOL Domain } & \multicolumn{2}{|c|}{$\begin{array}{c}<65 \text { years (a) } \\
\quad(n=23)\end{array}$} & \multicolumn{2}{|c|}{$\begin{array}{c}\geq 65 \text { years }(b) \\
\quad(n=17)\end{array}$} & \multirow[t]{2}{*}{$\begin{array}{c}\mathrm{p} \text { value between (a) } \\
\text { and (b) }\end{array}$} \\
\hline & Mean & $\mathrm{Sd}$ & Mean & $\mathrm{Sd}$ & \\
\hline \multicolumn{6}{|c|}{ HRQOL Domain Summary Scores } \\
\hline Urinary & 81.2 & 7.5 & 75.2 & 13.5 & 0.08 \\
\hline Bowel & 95.7 & 3.1 & 96.2 & 1.7 & 0.55 \\
\hline Sexual & 40.4 & 15.7 & 28.1 & 17.7 & $<0.03$ \\
\hline Hormonal & 90.9 & 11.3 & 90.7 & 9.1 & 0.95 \\
\hline \multicolumn{6}{|c|}{ Domain-Specific HRQOL Subscales } \\
\hline \multicolumn{6}{|l|}{ Urinary Subscales } \\
\hline Function & 81.4 & 10.5 & 75.0 & 17.4 & 0.16 \\
\hline Bother & 81.2 & 5.9 & 75.2 & 12.1 & $<0.04$ \\
\hline Incontinence & 77.6 & 8.1 & 66.9 & 9.4 & $<0.00$ \\
\hline Irritative/Obstructive & 85.9 & 4.2 & 86.5 & 12.9 & 0.84 \\
\hline \multicolumn{6}{|l|}{ Bowel Subscales } \\
\hline Function & 94.0 & 3.5 & 96.3 & 2.5 & $<0.03$ \\
\hline Bother & 97.0 & 2.0 & 96.2 & 0.8 & 0.13 \\
\hline \multicolumn{6}{|l|}{ Sexual Subscales } \\
\hline Function & 35.3 & 14.1 & 20.7 & 14.5 & $<0.00$ \\
\hline Bother & 51.9 & 14.0 & 44.9 & 12.1 & 0.11 \\
\hline \multicolumn{6}{|l|}{ Hormonal Subscales } \\
\hline Function & 86.1 & 15.5 & 84.8 & 9.8 & 0.76 \\
\hline Bother & 95.7 & 0.9 & 94.9 & 1.0 & $<0.01$ \\
\hline
\end{tabular}

After careful review of literature, in order to identify all available instruments for the evaluation of the impact of treatment of prostate cancer in quality of life, EPIC questionnaire was chosen, since it was the one that best approached our goals and was highly accepted in the international scientific community, and easy to use. Since EPIC was develo- ped to the American population, it was necessary to translate it and adapt it to Brazilian context and to test its measure proprieties.

Final version of translated EPIC (Appendix) maintained the English original title, since it is internationally recognized. It was added "Brazilian Version" to the title to facilitate the search in data bases. 
Tabela 5 - Correlation between the score and the EPIC segment postoperatively.

\begin{tabular}{|c|c|c|c|c|c|}
\hline \multirow[t]{2}{*}{ HRQOL Domain } & \multicolumn{2}{|c|}{$\begin{array}{c}<12 \text { months (a) } \\
n=14\end{array}$} & \multicolumn{2}{|c|}{$\begin{array}{c}\geq 12 \text { months (b) } \\
n=26\end{array}$} & \multirow[t]{2}{*}{$\begin{array}{l}\text { p value between } \\
\text { (a) and (b) }\end{array}$} \\
\hline & Mean & $\mathrm{Sd}$ & Mean & $S d$ & \\
\hline \multicolumn{6}{|c|}{ HRQOL Domain Summary Scores } \\
\hline Urinary & 73.9 & 9.5 & 81.6 & 10.7 & $<0.03$ \\
\hline Bowel & 99.2 & 1.6 & 95.0 & 3.0 & $<0.00$ \\
\hline Sexual & 35.1 & 14.9 & 35.2 & 17.3 & 0.99 \\
\hline Hormonal & 91.5 & 11.1 & 92.8 & 9.5 & 0.70 \\
\hline \multicolumn{6}{|c|}{ Domain-Specific HRQOL Subscales } \\
\hline \multicolumn{6}{|l|}{ Urinary Subscales } \\
\hline Function & 70.6 & 7.3 & 83.2 & 14.4 & $<0.00$ \\
\hline Bother & 75.6 & 10.7 & 80.3 & 7.6 & 0.11 \\
\hline Incontinence & 69.5 & 6.4 & 74.9 & 10.2 & 0.08 \\
\hline Irritative/Obstructive & 79.5 & 11.3 & 88.1 & 7.0 & $<0.01$ \\
\hline \multicolumn{6}{|l|}{ Bowel Subscales } \\
\hline Function & 98.2 & 2.5 & 94.4 & 3.6 & $<0.00$ \\
\hline Bother & 99.9 & 0.0 & 95.6 & 2.5 & 0.00 \\
\hline \multicolumn{6}{|l|}{ Sexual Subscales } \\
\hline Function & 29.9 & 13.6 & 28.7 & 14.7 & 0.80 \\
\hline Bother & 46.9 & 11.6 & 50.0 & 14.2 & 0.49 \\
\hline \multicolumn{6}{|l|}{ Hormonal Subscales } \\
\hline Function & 88.4 & 16.1 & 89.2 & 11.9 & 0.86 \\
\hline Bother & 94.6 & 1.5 & 97.4 & 1.4 & $<0.00$ \\
\hline
\end{tabular}

The patients that answered the questionnaire were invited to answer open question regarding each item in order to identify questions with difficult understanding. In general, the ins- trument was easy to apply and well accepted by the patients, with good efficacy.

The results obtained in the current study are consistent with the original and indica- 
te equivalency with the Brazilian version, with adequate reliability, high sensitivity to alterations. However, it is important to state that the questionnaire was used only for patients submitted to retropubic radical prostatectomy. In the present, another study comparing "open" to robotic-assisted laparoscopic radical prostatectomy is been carried out.

This questionnaire, after comparision of treatments, will be a resourceful tool for clinicals and researchers, to evaluate the impact of different treatmens on quality of life of pacients with prostate cancer.

\section{CONCLUSIONS}

Brazilian version of EPIC is valid and reliable as a new tool for the evaluation of the impact of retropubic radical prostatectomy in quality of life of Brazilian patients with localized prostate cancer, for national and international studies.

\section{APPENDIX}

The Expanded Prostate Cancer Index Composite (EPIC) - Brazilian version - Available at:

http://www.uroepm.com.br/setores/robotica.html

\section{CONFLICT OF INTEREST}

None declared.

\section{REFERENCES}

1. Ministério da Saúde. Instituto Nacional do Câncer - INCA. Incidência de Câncer no Brasil. Estimativa 2010. 2009. [cited ago 19, 2011]. Available at: http://www.inca.gov. br/estimativa/2010/index.asp?link=conteudo_view. asp\&ID $=5$.

2. Sociedade Brasileira de Urologia - SBU. Manual de Boas Práticas Urológicas. 2009. [cited ago 19, 2011]. Available at: http://www.sbu.org.br/pdf/manual_de_praticas_urologicas.pdf.
3. Ministério da Saúde. Instituto Nacional do Câncer - INCA Câncer de próstata. 2009. [cited ago 19, 2011]. Available at:http://www.inca.gov.br/conteudo_view.asp?id=339.

4. Presti JC. Neoplasias da próstata. In: Tanagho EA, McAninch JW. Urologia geral de Smith. 16a ed. Barueri: Manole; 2007; pp. 406-28.

5. Litwin MS, Hays RD, Fink A, Ganz PA, Leake B, Leach GE, et al.: Quality-of-life outcomes in men treated for localized prostate cancer. JAMA. 1995; 273: 129-35.

6. Miller DC, Sanda MG, Dunn RL, Montie JE, Pimentel H, Sandler HM,et al.: Long-term outcomes among localized prostate cancer survivors: health-related quality-of-life changes after radicalprostatectomy, external radiation, and brachytherapy. J Clin Oncol. 2005; 23: 2772-8.

7. Thiel Rdo R, Dambros M, Palma PC, Thiel M, Riccetto CL, Ramos M de F: Translation into Portuguese, cross-national adaptation and validation of the Female Sexual Function Index. Rev Bras Ginecol Obstet. 2008; 30: 504-10.

8. Farias N, Buchalla CM: A classificação internacional de funcionalidade, incapacidade e Saúde da Organização Mundial da Saúde: conceitos, usos e perspectivas. Rev Bras Epidemiol. 2005; 8: 187-93.

9. Michener LA, Snyder AR: Evaluation of health-related quality of life in patients with shoulder pain: are we doing the best we can? Clin Sports Med. 2008; 27: 491-505.

10. The WHOQOL Group. The Development of the World Health Organization quality of life assessment instrument (the WHOQOL). In: Orley J, Kuyken W, editors. Quality of Life Assessment: international perspectives. Heidelberg: Springer-Verlag. 1994: pp. 41-60.

11. Moreno AB, Lopes CS: Quality of life assessment in laryngectomized patients: a systematic review. Cad Saude Publica. 2002; 18: 81-92.

12. Wei JT, Dunn RL, Litwin MS, Sandler HM, Sanda MG: Development and validation of the expanded prostate cancer index composite (EPIC) for comprehensive assessment ofhealth-related quality of life in men with prostate cancer. Urology. 2000; 56: 899-905.

13. Guillemin F, Bombardier C, Beaton D: Cross-cultural adaptation of health-related quality of life measures: literature review and proposed guidelines. J Clin Epidemiol. 1993; 46: 1417-32.

14. Beaton DE, Bombardier C, Guillemin F, Ferraz MB: Guidelines for the process of cross-cultural adaptation of self-report measures. Spine (Phila Pa 1976). 2000; 25: 3186-91.

15. Duarte YA0. Família: Rede de suporte ou fator estressor. A ótica de idosos e cuidadores familiares. São Paulo, 2001. Tese (Doutorado) - Escola de Enfermagem, Universidade de São Paulo.

16. Lobiondo-Wood G, Harber J. Confiabilidade e validade. In: Lobiondo-Wood G, Harber J. Pesquisa em enfermagem: métodos, avaliação crítica e utilização. Rio de Janeiro: Guanabara Koogan. 2001. 
17. Pestana MH, Gagueiro JN: Análise de Dados para Ciências Sociais. 4. ed. Lisboa: Editora Sibalo. 2005.

18. George D, Mallery P. SPSS for Windows Step by Step. A Simple Guide and Reference. 11.0 Update. Boston: Allyn and Bacon. 2003.
19. Alexandre NM, Guirardello Ede B: Cultural adaptation of instruments utilized in occupational health. Rev Panam Salud Publica. 2002; 11: 109-11.

Correspondence address: Dr. Cássio Andreoni

Disciplina de Urologia - UNIFESP/EPM

Rua Napoleão de Barros, $715-2^{\circ}$ andar. CEP: 04024-002 - Vila Clementino - São Paulo / SP Tel.: (55) 11 - 5576-4086 - Fax: (55) 11 - 5572-6490

E-mail: cassio.andreoni@globo.com 